\title{
Development and validation of bioimpedance prediction equations for fat-free mass in unilateral male amputees
}

\author{
Hyuk-Jae Choi ${ }^{\text {Equal first author, } 1}{ }^{1}$, Chang-Yong Ko ${ }^{\text {Equal frrt author, }}{ }^{2}$, Yun Hee Chang ${ }^{1}$, Gyoo-Suk Kim ${ }^{1}$, Kyungsik Choi ${ }^{3}$, Chul- \\ Hyun Kim ${ }^{\text {Corresp. } 4}$ \\ 1 Department of Medical Convergence Research \& Development, Rehabilitation Engineering Research Institute, Incheon, Republic of Korea \\ 2 Department of Research \& Development, Refind Inc, Wonju, Gangwon-do, Republic of Korea \\ 3 Department of Healthcare Business Division, Healthmax company, Seoul, Gangnam-gu, Republic of Korea \\ 4 Department of Sports Medicine, Soonchunhyang University, Asan, Chungcheongnam-do, Republic of Korea \\ Corresponding Author: Chul-Hyun Kim \\ Email address: kimch37@sch.ac.kr
}

Background. Metabolic disease due to increased fat mass is observed in amputees (APTs), thereby restricting their activity. Systemic health management with periodic body composition (BC) testing is essential for healthy living. Bioelectrical impedance analysis (BIA) is a non-invasive and low-cost method to test BC; however, the APTs are classified as being exempted in the BIA.

Objective. We therefore developed five segmental estimated regression equations (sEREs) for determining fat-free mass (FFM, kg) suitable for APTs and aimed to improve the accuracy and validity of sERES.

Methods. Seventy-five male APTs participated in this cross-sectional study. Multiple regression analysis was performed to develop highly accurate sEREs of BIA based on independent variables derived from anthropometric measurements, dual-energy X-ray absorptiometry (DXA), and BIA parameters. The difference in validity between the predicted DXA and sum of the segmentally-predicted FFM values by sEREs (Sum_sEREs) values was evaluated using bivariate linear regression analysis and the Bland-Altman plot.

Results. The coefficient of determination $\left(R^{2}\right)$ and total error (TE) between DXA and Sum_sEREs were $71 \%$ and $5.4(\mathrm{~kg})$ in the cross-validation analysis.

Conclusions. We confirmed the possibility of evaluating the FFM of APTs through the SEREs developed in this study. We also identified several independent variables that should be considered while developing such SEREs. Further studies are required to determine the validity of our sEREs and the most appropriate BIA frequencies for measuring FFM in APTs. 
1 Development and validation of bioimpedance prediction equations for fat-free mass in unilateral male

2 amputees

3

4 Hyuk-Jae Choi ${ }^{1}$, Chang-Yong Ko ${ }^{2}$, Yun Hee Chang ${ }^{1}$, Gyoosuk Kim ${ }^{1}$, Kyungsik Choi ${ }^{3}$, Chul-Hyun Kim ${ }^{4}$ 5

$6 \quad{ }^{1}$ Department of Medical Convergence Research \& Development, Rehabilitation Engineering Research

7 Institute, Incheon, Republic of Korea

$8 \quad 2$ Department of Research \& Development, Refind Inc., Wonju, Gangwon-do, Republic of Korea

$9{ }^{3}$ Department of Healthcare Business Division, Healthmax Company, Seoul, Republic of Korea

$10{ }^{4}$ Department of Sports Medicine, Soonchunhyang University, Asan, Chungcheongnam-do, Republic of

11 Korea

12

13 Corresponding Author:

14 Chul-Hyun $\mathrm{Kim}^{4}$

1522 Soonchunhyangro, 31438 Asan, Chungcheongnam-do, Republic of Korea. Email address:

kimch37@sch.ac.kr

Abstract

Background. Metabolic disease due to increased fat mass is observed in amputees (APTs), thereby restricting their activity. Systemic health management with periodic body composition (BC) testing is essential for healthy living. Bioelectrical impedance analysis (BIA) is a non-invasive and low-cost method to test BC; however, the APTs are classified as being exempted in the BIA. Objective: We therefore developed five segmental estimated regression equations (sEREs) for determining fat-free mass (FFM, kg) suitable for APTs and aimed to improve the accuracy and validity of 25 sEREs.

26 Methods. Seventy-five male APTs participated in this cross-sectional study. Multiple regression analysis 27 was performed to develop highly accurate sEREs of BIA based on independent variables derived from 28 anthropometric measurements, dual-energy X-ray absorptiometry (DXA), and BIA parameters. The 29 difference in validity between the predicted DXA and sum of the segmentally-predicted FFM values by 30 sEREs (Sum_sEREs) values was evaluated using bivariate linear regression analysis and the Bland31 Altman plot.

32 Results. The coefficient of determination $\left(R^{2}\right)$ and total error $(T E)$ between DXA and Sum_sEREs were $3371 \%$ and $5.4(\mathrm{~kg})$ in the cross-validation analysis. 
34 Conclusions. We confirmed the possibility of evaluating the FFM of APTs through the sEREs developed

in this study. We also identified several independent variables that should be considered while developing such sEREs. Further studies are required to determine the validity of our sEREs and the most appropriate BIA frequencies for measuring FFM in APTs.

\section{Introduction}

Amputation refers to the removal of the upper or lower extremities to resolve the cause of a disability due to disease or trauma (Hecht et al. 2003). Physical and functional constraints are more severe in amputees (APTs) than in the general population (Coffey et al. 2014). Previously, most amputations were performed following war-related or occupational injuries. Indeed, an increase in the number of APTs was observed following World War II and the Iraq War (Kulkarni et al. 1998; Robbins et al. 2009).

In addition, cardiovascular diseases such as high blood pressure/stroke and metabolic diseases including diabetes mellitus may necessitate amputation (Kopelman 2000; Rahman \& Berenson 2010). Currently, reports suggest that the rate of amputation continues to increase worldwide. Notably, the number of APTs in the United States is predicted to increase from approximately 1.6 million (2008 data) to 3.6 million by 2050 (Ziegler-Graham et al. 2008).

Diabetes is associated with impaired blood supply to the extremities, which may lead to necrosis or severe ulcers that necessitate amputation (Mishra et al. 2017). Post-amputation complications, such as atrophy, phantom limb pain, and contracture, may lead to further activity constraints beyond those imposed by the amputation, thereby exerting deleterious effects on one's overall health (Gallagher et al. 2001; O'Sullivan et al. 2013; Ustun et al. 2003). Additional post-amputation complications include obesity or excessive fat accumulation (Kurdibaylo 1996), atrophy due to decreased muscle mobilization for ambulation and joint stability, and decreased physical strength (Centomo et al. 2008) (Isakov et al. 1996) (Renstrom et al. 1983a) (Renstrom et al. 1983b) (Sadeghi et al. 2001) (Bukowski 2006) (Zachariah et al. 2004).

These complications may lead to an overall deterioration in physical health, which can be reflected by changes in BC and muscle condition, ultimately resulting in a decreased quality of life (Chin et al. 2002) (Rosenberg et al. 2013) (Suk et al. 2001). Periodic assessments of BC and weight management interventions are critical for preventing secondary complications of amputation, such as excessive body fat/obesity (Stone et al. 2006) (Yoo 2014). Such assessments and interventions may not only help prevent obesity and muscle atrophy, but may also improve overall physical/mental health and quality of life. Dual-energy X-ray absorptiometry (DXA) allows the measurement of bone mineral content (BMC), fat mass (FM), and soft lean tissue mass (SLTM) by passing two X-ray beams through the body. Although DXA is a highly accurate, validated method for the assessment of fat-free mass (FFM) (i.e., 
$\mathrm{BMC}+\mathrm{SLTM})$, these assessments are time-consuming and expensive. Furthermore, DXA requires exposure to small amounts of radiation, and some participants may be uncomfortable given the limited measurement space. Despite these limitations, DXA continues to be widely touted as the gold standard for determining BC (Janssen et al. 2002) (Lee \& Gallagher 2008) (Woodrow 2009).

Commercially available bioimpedance devices include single- and multi-frequency impedance analysis (SFBIA and MFBIA) and bioimpedance spectroscopy (BIS) (Mulasi et al. 2015). The principle of bioelectrical impedance analysis (BIA), including SFBIA, MFBIA, and BIS methods is to determine electrical impedance as "resistance $(R)$ " (Kyle et al. 2004a) for total body water (TBW) and "reactance (Xc)" for body cell mass (Walter-Kroker et al. 2011). BIA is advantageous in that it is faster, more useful, less invasive, less physically restrictive, and less expensive than DXA. In addition, BIA equipment occupies far less space and requires less effort to operate than DXA equipment with a non-portable nature, which limits its use (Buckinx et al. 2015) (Janssen et al. 2002). As a routine clinical BIA tool, BC analysis was now readily available in a wider range of clinics and in the community (Ward 2019). Given these advantages, BIA is performed in various settings. To estimate BC, BIA devices measure TBW content by sending a micro-current of less than $800 \mu \mathrm{A}$ throughout the body. An estimated regression equation (ERE) is then used to predict FM and FFM (kg) (Kyle et al. 2004a). Recently, BIA has been used for the quantitation of $\mathrm{BC}$ through a specific mathematical model without empirically derived variables for athletic players (Sardinha et al. 2020) (Campa \& Toselli 2018; Toselli et al. 2020), children (Colica et al. 2018), older adults (Silveira et al. 2020), and young patients with cystic fibrosis (Charatsi et al. 2016).

However, APTs are typically excluded from such BIA studies owing to differences in limb length between the amputated and sound sides and irregular limb shapes (Dogan et al. 2012) because the height is different and it is against the impedance index (ZI) formula (height $\mathrm{t}^{2} /$ impedance), which is a more significant single predictor of FFM than other anthropometric variables (Nguyen et al. 2007). Thus, the use of BIA equations based on individuals (Beaudart et al. 2020) without amputation may not be accurate and not be a valid measurement when applied in APTs.

In general, $\mathrm{BC}$ is predicted through variables considering the whole-body height on the wrist-ankle method for reducing typical BIA errors.

However, we intend to proceed with a study on the ERE of APT through the variable of the ZI considering the segmental length based on Tanaka's research (Tanaka et al. 2007). Appropriate segmental estimated regression equation (sERE) for BC in APTs should thus consider residual limb properties length and various other factors as independent variables including age, height, weight, gender, $Z I, R, X c$, and phage angle $(P A)$ without segmental amputated limb weight that is not measurable. 
101 In this study, the InBody S10 BIA instrument (InBody S10) was used. This instrument allows for the

102 analysis of various cellular properties through frequencies segmentally. It is actually placed at eight

103 precise tactile points with an adhere-type electrode to perform BIA in the comfortable and safe supine

104 position for ATPs.

105 Therefore, in the present study, we aimed to develop an ERE for BIA in APTs using DXA measurements

106 as the reference standard. The development of a valid ERE for use in APTs may improve health

107 management by providing more accurate and convenient assessments of FFM through BIA. We

108 confirmed the possibility of evaluating FFM of APTs through the sERE developed in this study. For an

109 overview of abbreviations and parameters, see Table 1.

110

111

112 Materials \& Methods

113 Participants: This study was approved by the Institutional Review Board (No. 1040875-201707-SB-030).

114 After receiving a complete description of the study, all participants provided written informed consent.

115 A total of 75 male APTs were recruited and the sERE development was applied to them. A total of 75

116 individuals who were unilateral APTs were included in the study. The mean participant age was $43.6 \pm 12$

117 years. Seventeen participants had previously undergone upper limb amputation (trans-humeral

118 amputation: $\mathrm{n}=5$; trans-radial amputation: $\mathrm{n}=12$ ), and 58 had previously undergone lower limb amputation

119 (trans-femoral amputation: $n=32$; trans-tibial amputation: $n=26$ ). APTs with disarticulation and

120 multilateral (bi-, tri-) amputation were excluded. Additional participant characteristics including residual

121 limb length $(\mathrm{cm})$ and onset (postoperative period, years) are presented in Table 2.

122

123 Experimental device (DXA): DXA (Lunar Corp., Madison, WI, USA) measurements of FFM were used as

124 the reference standard in the development of the ERE. This instrument was calibrated through the spine

125 phantom provided by the manufacture daily. To standardize the scan, files from the original DXA system

126 were transferred to iDXA software, version 4.0.2. The scan process was blinded and fulfilled by one

127 radiologist who wore protective clothing. The segmentation method based on Heymsfield et al. (1990)

128 was applied to uniform measurement (Heymsfield et al. 1990).

129 Participants were instructed to wear comfortable clothing for the assessment. Under the guidance of a

130 professional examiner, each participant lay comfortably in the supine position on the assessment table,

131 following which they were asked to spread both the upper and lower limbs. Whole-body DXA was

132 performed for approximately $15 \mathrm{~min}$.

133

134 Experimental device (BIA): BIA of the tetrapolar 8-point electrode type (InBody S10 for the supine 135 measure, InBody Co. South Korea) was performed in this study. This BIA model uses eight electrodes 
136 positioned at each hand and foot and enables multifrequency impedance measurement of the arms, trunk,

137 and legs. Impedance parameters were measured with alternating current of 80 and $100 \mathrm{~mA}$ at frequencies

138 of 1, 5, 50, 250, 500, and $1000 \mathrm{kHz}$ for InBody S10. After checking the precision error of FFM about

139 repeatability through biplicate measurements by same APT based on previous study (Buckinx et al.

140 2015), the InBody S10 was used, which was designed for single measurements in the supine position and

141 operated using eight electrodes on the right and left upper and lower sides while being in the supine

142 position on a non-conductive surface through an SFBIA of only $50 \mathrm{kHz}$. In the sound limb, adhesive gel

143 electrodes were placed at defined anatomical sites cleaned with alcohol before attaching the electrode on

144 the dorsal surfaces of the hand, wrist, ankle, and foot as follows: the proximal edge of the wrist electrode

145 was attached from an imaginary line bisecting the styloid process of the ulna and the proximal edge of the

146 finger electrode on an imaginary line from the imaginary line bisecting the metatarsophalangeal joint of

147 the middle finger. The proximal edge of the ankle electrode was attached from an imaginary line bisecting

148 the medial malleolus and the distal edge of the toe electrode was placed from an imaginary line through

149 the metatarsophalangeal joints of the second toe as shown in Figure 1b. In the residual limb, the distal and

150 proximal electrodes were attached from the end of the stump (=distal part) to the region (=proximal part)

151 by keeping the distance according to the instructions of InBody S10. Additionally, fixed-distance of

152 electrodes was used with a 5-cm standard distance as shown in Figure 1c (Kaysen et al. 2005; Kriemler et

153 al. 2009). The device was calibrated every morning using the standard control circuit supplied by the

154 manufacturer. We confirmed that the precision error was less than $2 \%$ (Figure 1).

155

156

Definition of segmental ZI (ZI) and regions of interest (ROI) in DXA: Impedance indices (ZI) for each

157 body part were determined considering the residual limb length in each participant. $Z I$ values were

158 calculated in accordance with methods described by Tanaka et al. (Tanaka et al. 2007). As shown in

159 Equation 1, ZI was calculated by dividing height ${ }^{2}$ by $Z$ (based on values for non-APTs). We then

160 calculated the body part length $Z I\left(Z I_{\mathrm{BPL}}\right)$ by dividing the body part length (BPL) ${ }^{2}$ by $Z$. (Tanaka et al.

161 2007). BPL was measured for the following five areas: left arm (LA), right arm (RA), left leg (LL), right

162 leg (RL), and trunk (TR). The reference positions for the lengths of the upper/lower limbs and trunk were

163 defined as follows: the area between the humeral head (=acromion) and styloid processes of the wrist

164 (ulna) for the upper limbs; the area from the anterior superior iliac spine to the medial malleoli for the

165 lower limbs; and the posterior length between the seventh cervical vertebra prominens to the center of the

166 posterior superior iliac spine for the trunk (Beattie et al. 1990) (Hackenberg et al. 2003) (Jamaluddin et al.

167 2011) (Lee et al. 2016) (Neelly et al. 2013) (Ross 1972). The results of the experiment were analyzed by

168 matching the physical measurements to the BIA electrode locations and DXA ROI based on these

169 measurement standards.

Peer) reviewing PDF | (2020:10:53446:2:0:CHECK 21 Jan 2021) 
170 According to the Heymsfield's protocol (1990), the boundaries of the ROI are defined as follows: 1) for

171 the upper limbs of the ROI (right and left), the arms are isolated by running a line through the humeral

172 head and 2) for the lower limbs, the pelvis cut is placed just above the pelvic brim and the computer

173 automatically draws the lower pelvic lines to bisect the hip joints (Heymsfield et al. 1990; Jeon et al.

174 2020).

175

$$
Z I=\frac{H^{2}}{Z}
$$

(Equation 1)

H: Height of the whole body, Z: Impedance

176

$$
Z I_{B P L}=\frac{B P L^{2}}{Z}
$$

(Equation 2)

BPL: Body part length, Z: Impedance

177

178

179

180

181

182

183

184

185

186

187

188

189

190

191

192

193

194

195

196

197

Independent variables for segmental BIA: Independent variables included in the EREs were determined for the five body areas as follows: $R$ was applied by differentiating among the LA $\left(R_{\mathrm{LA}}\right), \mathrm{RA}\left(R_{\mathrm{RA}}\right), \mathrm{LL}$ $\left(R_{\mathrm{LL}}\right), \mathrm{RL}\left(R_{\mathrm{RL}}\right)$, and trunk $\left(R_{\mathrm{TR}}\right)$. Using notations identical to those for $R$, impedance $(Z)$, reactance $(X c)$, and PA were also calculated for each body part and expressed in terms of $R_{\mathrm{BPL}}, Z_{\mathrm{BPL}}, X c_{\mathrm{BPL}}$, and $P A_{\mathrm{BPL}}$.

Experimental procedures: Prior to the measurements of FFM, participants were instructed to abstain from excessive dehydration-accompanied exercises and excessive alcohol use. In addition, they were instructed to fast for at least $6 \mathrm{~h}$ and to abstain from drinking for at least $4 \mathrm{~h}$.

We checked that the urinary bladder was voided in all participants within 30 minutes before measurement, and we ensured that all participants wore non-conductive and comfortable sportswear. All conductive materials, prosthetic limbs, and amputation covers (silicone, amputation protection, etc.) were removed. First, DXA and then BIA test were measured consistently. For the measurements, after lying on a DXA sheet, stability (stabilization of BC) measurement was taken for $5 \mathrm{~min}$ in the supine position considering the potential for variable fluid shifts, and the DXA scan was performed, and BIA was measured on the place immediately after the DXA scan without changing the position. All participants maintained an abduction angle of approximately $15^{\circ}$ for the shoulder and hip joints. The elbow and knee joints were extended in a straight anatomical position. The physical contact of each electrode was ensured in accordance with the criteria recommended by the manufacturer. Each measurement took approximately 5-15 min. Participants were instructed to maintain a comfortable position without any movement during the examination (Brantlov et al. 2017; Kyle et al. 2004d). 
Sum of the segmentally-predicted FFM values by sERE (Sum_sEREs): After the development of the

200

201

202

203

204

205

206

207

208

209

210

211

212

213

214

215

216

217

218

219

220

221

222

223

224

225

226

227

228

229

230

231

sEREs of the five body parts in the APTs, the sum of the segmentally-predicted FFM values by sERE was calculated. We confirmed the validity and accuracy between DXA and the sum of sERE_BIA about FFM through bivariate linear regression and the Bland_Altman plot.

Statistical analysis: The physical characteristics of the APTs group are presented as means with SDs. For confirming the normality test, if there are fewer than 30 people, the normality test is required, but the number of participants was 75; therefore, we assumed normality and analyzed all data (Kwak \& Kim 2017;

Sang Gyu et al. 2019). The forward stepwise multiple linear regression analysis was used to develop sEREs in the APTs group. The significance level was set to $p \leq 0.05$. Variables included in the initial analyses contained $Z I_{B P L}, R_{B P L}, X c_{B P L}, P A_{B P L}$, age (yr), height $(\mathrm{cm})$, and weight $(\mathrm{kg})$. The developmental equations were selected by measures of goodness-of-fit statistics, including coefficient of determination $\left(R^{2}\right)$, the standard error of estimate (SEE), acceptable subjective rating of SEE (i.e. good to excellent) according to the minimally acceptable standard for prediction errors (Buckinx et al. 2018; Heyward 2004; Lohman 1992a), and the variance inflation factor (VIF). The SEE measures the variation in the actual values from the predicted values. The SEE represents the degree of deviation of individual scores form the regression line. It is computed using the following formula:

$\mathrm{SEE}=\sqrt{\sum(\text { Measured FFM - Estimated FFM })^{2} /(N-p-1)}$ where $p=$ number of predicter variables. The VIF assesses how much the variance of an estimated regression coefficient increases when predictors are correlated for estimating collinearity/multicollinearity. In case of higher values of more than 10, it can be assumed that the regression coefficients are poorly estimated due to multi-collinearity to remove predictors from the model. In our study, with values less than 10 (Lee et al. 2018; Wickramasinghe et al. 2008), we could proceed with our regression analysis. In the cross-validation, the group predictive accuracy of the Sum_sEREs was tested by calculating $R^{2}$, total error (TE: The TE represents the degree of deviation from the line of identity using the formula: Total Error = $\sqrt{\sum(\text { Measured FFM - Estimated FFM })^{2} / N}$ ) and acceptable subjective rating of TE (Heyward \& Wagner 2004; Lohman 1992b). The individual predictive accuracy of these equations was also tested by Bland-Altman plots that includes the bias of the mean difference between measured values of DXA and predicted values of Sum_sEREs. We used the 95\% limits of agreement (LOA) between equations, and concordance correlation efficient $\left(r_{\mathrm{y}-\mathrm{y}, \text {,mean }}\right)$. Data were analyzed using Microsoft Office Excel Ver. 2013 (Microsoft, Redmond, WA, USA) and SPSS version 18.0 (IBM, USA).

Results

Peer) reviewing PDF | (2020:10:53446:2:0:CHECK 21 Jan 2021) 
232 Segmental Estimated Regression Equation

233 DXA measurements of FFM were used as the dependent variable in the development of the EREs for use

234 in APTs. Various independent variables were entered to ensure optimal model development. Our model

235 considered factors such as $R^{2}$, multicollinearity (tolerance and variance inflation factor [VIF]), and

236 standard error estimates (SEE). Using these factors, we developed sEREs for the left and right

237 upper/lower limbs as well as the trunk. $Z I_{\mathrm{LA}}, X c_{\mathrm{LA}}$, height, and age were entered as independent variables

238 in the final sERE model for FFM in the left arm $\left(\mathrm{LA}_{\mathrm{FFM}}\right)$. Values for the final sERE for $\mathrm{LA}_{\mathrm{FFM}}$ were as

239 follows: $R=0.95, R^{2}=0.90$, and adjusted $R^{2}=0.89 . Z I_{\mathrm{RA}}$ and $X c_{\mathrm{RA}}$ were entered as independent variables in

240 the final sERE model for FFM in the right arm.

241 Values for the final sERE for $\mathrm{RA}_{\mathrm{FFM}}$ were as follows: $R=0.86, R^{2}=0.74$, and adjusted $R^{2}=0.73 . R_{\mathrm{BPL}}, X c_{\mathrm{BPL}}$,

$242 Z I_{\mathrm{BPL}}$, and weight were entered as independent variables in the final models for both the left and right

243 lower limbs. The $\mathrm{LL}_{\mathrm{FFM}}$ model included $R_{\mathrm{LL}}, X c_{\mathrm{LL}}, Z I_{\mathrm{LL}}$, and weight. The final sERE values for $\mathrm{LL}_{\mathrm{FFM}}$ were

244 as follows: $R=0.95, R^{2}=0.91$, and adjusted $R^{2}=0.90$. The highest correlation coefficients were observed for

$245 \mathrm{RL}_{\mathrm{FFM}}: R=0.97, R^{2}=0.94$, and adjusted $R^{2}=0.93$. In contrast, the lowest correlation coefficients were

246 observed for $\mathrm{TR}_{\mathrm{FFM}}: R=0.88, R^{2}=0.78$, and adjusted $R^{2}=0.76$. A total of five independent variables were

247 entered for the TR $\mathrm{FFM}_{\mathrm{F}} \mathrm{ERE}: \mathrm{ZI}_{\mathrm{TR}}$, weight, height, age, and $R_{\mathrm{TR}}$ (Table 3).

248

249

Cross-Validation between BIA and DXA about FFM

250

251

252

253

254

255

256

257

258

259

260

261

262

Linear regression, total error, and line of identity: Linear regression analyses were used to calculate the correlation between BIA estimates based on the final segmental ERE and standard DXA measurements. In the total error (TE) calculation (Equation 3), $\mathrm{Y}-\mathrm{Y}^{\prime}$ represents the difference between the DXA measurement (Y) and the BIA estimate ( $\left.\mathrm{Y}^{\prime}\right)$, while $\mathrm{N}$ represents the sample size.

$$
T E=\sqrt{\sum\left(\mathrm{Y}-\mathrm{Y}^{\prime}\right)^{2} / N}
$$

The $T E$ for the comparison between DXA and BIA values for FFM was $5.4(\mathrm{~kg})$, with a correlation of $0.84(p<0.05)$ (Fig. 1).

Residuals and bias in Bland-Altman plots: To evaluate the validity of the final ERE, the residuals (i.e., the difference between BIA-estimated and DXA-measured FFM) and means of the two methods were assessed using the Bland-Altman plot (Fig. 2). The bias of the difference between the two FFM measurements was $-4.60 \mathrm{~kg}$. BIA estimates obtained using the ERE tended to be higher than those obtained using DXA values. Furthermore, there was a tendency for the residuals of the bias to be evenly distributed, and increased bias tended to be associated with decreased residuals. 
263 DiscussionIn the present study, we aimed to develop sERE for BIA in APTs using DXA measurements as

264 the reference standard. Given the correlation $(\mathrm{r}=0.85), T E(5.4 \mathrm{~kg})$, and coefficient of determination

$265\left(R^{2}=71 \%\right)$ between FFM values obtained using Sum_sEREs and DXA, our findings confirmed that the

266 sERE developed in this study could assess FFM in APTs.

267 Based on findings obtained in previous studies, gender differences should be considered in the selection

268 of independent variables to obtain more accurate estimates (Beaudart et al. 2020). However, this study

269 was conducted on only male APTs excluding female because of a difference in the gender ratio within the

270 total APTs recruited; hence, representativeness of gender could not be achieved. Furthermore, data from

271 the Multidimensional Body-Self Relations Questionnaire suggest that women experience significantly

272 higher level of dissatisfaction with their bodies than do men following amputation (Holzer et al. 2014).

273 For the above reasons, Thus, our sEREs were developed using data from male APTs only.

274 The process of developing sERE was carried out by applying the FFM of DXA on both the dominant

$275 \mathrm{limb}$ and the same limb BIA variables or vice versa. Therefore, the dominant and non-dominant limbs

276 were not considered specifically. Additionally, in the process of validation of the developed sERE for

277 each limb, the same limb variables were applied.

278 There are examples for various types of amputation for uni-, bi-, and multi-lateral APTs. However, in this

279

280

281

282

283

284

285

286

287

288

289

290

291

292

293

294

295

296 study, for the development of a basic sERE, only unilateral APTs were included to control the length variable of the amputated site. Given the difficulty in controlling for the BPL among multilateral APTs, we also restricted our participants to unilateral APTs.

The measurement range of the InBody S10 device (Biospace, Korea) extends from 5 to $1000 \mathrm{kHz}(1,5$, $50,250,500$, and $1000 \mathrm{kHz}$ ). MFBIA can more accurately measure intra- and extracellular body water than SFBIA of $50 \mathrm{kHz}$. However, SFBIA of $50 \mathrm{kHz}$ is better for measuring cell membrane properties through Xc. Because, it provides equivalence of information for the function of Xc at $50 \mathrm{kHz}$ versus other frequencies (Piccoli et al. 2005). For developing basic sERE of APTs, we carefully analyzed the cell membrane state of the APT rather than analyzing between the intra- and extracellular body water properties (Kyle et al. 2004b) (Heymsfield et al. 2005). Only an SFBIA of $50 \mathrm{kHz}$ was used for the calculation of total body water, on which estimations for FFM are based using proprietary equations (Achamrah et al. 2018).

Previous BIA studies have excluded APTs as well as patients with joint deformation, hemi-paralysis, and uncommonly large/small bodies (Dogan et al. 2012) (Kyle et al. 2004e) (Mialich et al. 2014). Tanaka et al. (2007) proposed using a tetrapolar 4-point BIA to measure BC in such individuals (Mialich et al. 2014) (Tanaka et al. 2007).

However, in a 4-point BIA with the tetrapolar system, the electrodes are attached manually by connecting electrodes to measure the segments according to manufacturer's instructions. Four-point estimates are 
297 derived based on the characteristics of the flow of current on one side of the body, allowing for the 298 calculation of BC for the specific body part, following which total estimates are obtained. Thus, the 299 measurements had substantial systematic errors, including underestimation or overestimation of accuracy 300 (Janssen et al. 2000) (Tanaka et al. 2007). Given the errors of the tetrapolar 4-point BIA, Foster and 301 Lukaski (1996) highlighted the need for further research regarding the use of such measurements for the 302 analyses of BC (Lukaski 1996). To avoid these issues, we utilized the tetrapolar 8-point segmental BIA 303 (sBIA) as InBody S10, in which the pairs of electrodes are attached to measure the different body 304 segments.

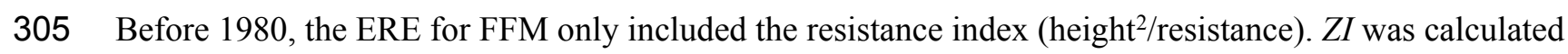
306 by taking into account the variables for the whole-body height in ERE of non-APTs. However, the sERE 307 of APT developed in this study was analyzed by applying $Z I_{B P L}$ and BIA parameters considering the 308 length of each body part, including the residual limbs and condition of this amputated region.

309 In five sEREs for each part, the redundancy of variables was considered through VIF and the highly 310 accurate sEREs calculated through a meticulous analysis process based on the BIA characteristics that 311 affect the APT.

312 The BIA variables applied to the sEREs are $R, X c$, and $Z$ as shown in Table 3. we were to confirm that a 313 complex quantity composed of $(R)$ which is caused by TBW, and capacitance of the cell membrane 314 related to $(X c)$, and obstruction to the flow of an alternating current $(Z)$ that was dependent on the 315 frequency of the applied current based on the theoretical basis of BIA in the limbs of APT (Kyle et al. 316 2004a; Kyle et al. 2004c) (Khalil et al. 2014).

317 Generally, assuming our body as a cylinder, both arms and legs are attached to the body, and the whole318 body height is used for the $Z I\left(Z I=\right.$ Height $\left.^{2} / Z\right)$. However, in this APT study, the length of each limb was 319 substituted for the $Z I$ of each $\operatorname{limb}\left(Z I_{\mathrm{BPL}}=\mathrm{BPL}^{2} / Z\right)$ in order to make the estimation equation of the 320 segmental limb considering amputated extremity. For example, in the process of developing estimating 321 equations, such as the FFM of each of the right upper and left upper limbs etc., the final model with a low 322 statistical error and a high estimating power was selected using the length and BIA variables of the same 323 body part. The APTs had imbalance between the left and right limbs, similar to that reported in a previous 324 study (Sherk et al. 2010), showing muscle and fat imbalance between the injured and sound limb; 325 consequently, there was a difference in variables entered in the final sERE obtained from the final model 326 selected as the criterion of the significance level $(P<0.05)$, VIF $(<10)$, SEE, and $R^{2}$.

327 In the present study, we utilized a forward stepwise multiple regression analysis that included diverse 328 independent variables such as residual limb length. When developing an ERE, approximately 20 329 participants are required for each independent variable entered. Given that our study included 75 
330 participants, four or fewer independent variables are considered appropriate (Heyward \& Wagner 2004).

331 These independent variables included $\mathrm{ZI}_{\mathrm{BPL}}$, height, weight, age, onset, and segmental BIA factors.

332 Table 3 shows the final EREs. The number of variables entered in each sERE ranged from two to five.

333 Although previous studies have specified that only four variables should be included, based on our

334 sample size, it was necessary to consider factors, such as $R^{2}$, multicollinearity (tolerance and VIF), and

335 SEE, to develop the most ideal model. Nonetheless, the sERE for the trunk was the only equation to have 336 been developed using five variables.

337 BIA estimates of FFM are based on TBW measurements, which are derived from $Z$ values obtained by 338 passing microcurrents throughout the human body. In this calculation, the human body is assumed to be 339 cylindrical (TBW $=\rho \times$ height $^{2} / Z, \rho=$ constant). Based on the theory that TBW comprises $73 \%$ of FFM $340(\mathrm{TBW}=\mathrm{FFM} \times 0.73)$, the estimates of FFM can be obtained using the following equation: $\mathrm{FFM}=$

341 TBW/0.73. Factors, such as race, age, sex, and medical history, influence the unique conduction constant

342 ( $\rho$ ) as well as the correlation between TBW and ZI, making it necessary to include several independent

343 variables in the TBW calculation (Kyle et al. 2004b). Therefore, in this study, we included additional

344 independent variables, such as onset and characteristics of the body part amputated.

345 Several BIA studies conducted outside of Korea have included patients with hemi-paralysis(Kafri et al.

346 2014) (Nalepa et al. 2019) (Yoo et al. 2016), pediatric scoliosis (Matusik et al. 2016), or Turner's

347 syndrome (i.e., abnormally small body)(Guedes et al. 2010). However, no such studies have been

348 conducted on the APTs. Despite this, studies have recommended that BIA measurements be obtained in

349 the non-amputated limb (Kyle et al. 2004e) (Mialich et al. 2014).

350 However, to estimate the whole-body FFM, the amputated body parts must be considered. In our study,

351

352

353

354

355

356

357

358

359

360

361

362

363 the sEREs for FFM did not exhibit a close relationship with $P A_{\mathrm{BPL}}$, and we did not include PA as an independent variable for any ERE in Table 3, similar to models developed using data from the general population (Mialich et al. 2014). Meanwhile, $X c$ has been utilized in numerous EREs for FFM in studies conducted outside Korea (Lieberman 1993) (Kyle et al. 2001) (Roubenoff et al. 1997) (Stolarczyk et al. 1994).

In accordance with previous findings, our sERE for FFM exhibited a close relationship with $X c$, whereas onset did not appear to exert a significant impact on FFM estimates. Although changes in BC occur over time following amputation, FFM can be maintained with systematic rehabilitation and BC management during the first postoperative year. This was noted by a previous study of those for whom 2 to 15 years had passed since amputation (Eckard et al. 2015; Renstrom et al. 1983b).

In our study, the final sEREs were selected by considering factors, such as $R^{2}$, tolerance, VIF, and SEE. As shown in Figure 2, the correlation for FFM values was high $(R=0.84)$, with an $R^{2}$ of $71 \%$. This correlation is higher than the standard of $0.80\left(R^{2}=64 \%\right)$ suggested by Heyward and Wagner (Heyward \& 
364 Wagner 2004) for validity research. A bivariate linear regression equation ( $Y=a X \pm b)$ was used to

365

366

367

368

369

370

371

372

373

374

375

376

377

378

379

380

381

382

383

384

385

386

387

388

389

390

391

392

393

394

395

396

397 confirm the accuracy of Sum_sEREs as well as the correlation. The slope (a) and y-intercept (b) were used to analyze the correlation between DXA and BIA measurements. The slope of the bivariate linear regression equation was 0.89 , whereas the $y$-intercept was 1.60 , yielding a simply positive correlation of $y$ $=\mathrm{x}$. However, the slope of 0.89 exhibited a positive correlation that was close to the standard of 1 .

Furthermore, the y-intercept was close to the ideal standard of 0 . Taken together, these results suggest the possibility of sERE for APT.

Individual errors for DXA and BIA results are shown in the Bland-Altman plot in Figure 3. The average value representing the difference between the two methods (i.e., Bias) was $-4.60 \mathrm{~kg}$. When the bias approaches $0(\mathrm{y}=0)$, there is no mean difference in the measurement values with an ideal validity. However, bias did not approach 0 in our study. BIA tended to overestimate FFM, relative to the value obtained using DXA. Ainsworth (1997) suggested that the results are ideal if the proportion that exceeds the standard of overestimation and underestimation is less than 30\% (Ainsworth et al. 1997). In our study, the proportion of APTs who exceeded the standard of bias was $50.7 \%$, suggesting a need for further validity studies.

\section{Limitation}

We used 50kHz to characterize the cell membrane. We will proceed with the MFBIA study including 1, $50,250,500,1000 \mathrm{kHz}$, and over frequencies, as a future research project. In this study, limitations were placed on the use of only $50 \mathrm{kHz}$ frequency. In this study, a single frequency of $50 \mathrm{kHz}$ was used to explain the characteristics of homeostasis for cell membrane well, but ICF and ECF have limitations in reflecting the characteristics at a normal level. In this study, limitations were placed on the use of only 50 $\mathrm{kHz}$ frequency. In validation procedure, we recognized importance of validating method through a split group design, K-fold or LOOV-type. However, without external cross-validation through group of predictive power test, only the sEREs were developed. We confirmed only cross-validation between DXA and Sum_sEREs of FFM values as a limitation. This study was considered to be possible study of APT's sERE for the first time, and we would plan to conduct a validation study by recruiting more APTs in future studies. In this study, we did not perform a thoughtful analysis of the PA, but it will be done for the healthcare of the APTs in the future.

\section{Conclusions}


398

399

400

401

402

403

404

405

406

407

408

409

410

411

412

413

414

415

416

417

418

419

420

421

422

423

424

425

426

427

428

429

430

431

432

433

434

435

436

437

438

439

In the present study, we utilized multiple regression analysis to develop an sERE for FFM in APTs, using DXA as the reference standard. There were bias (-4.598), and LOA (-10.26 1.06) as deficiencies in the results of this study. However, the minimal clinical feasibility may be confirmed based on the coefficient of determination $\left(R^{2}=71 \%\right)$, and $T E(5.40 \mathrm{~kg})$. The accuracy is not high, but the possibility of using it has been confirmed. We processed meaningful study as a sERE of APTs excluded subjects from the past. It is believed to be basically possible research of APT's sERE.

In addition, we identified several independent variables that should be considered while developing such sERE for APT. Further studies are required to determine the validity of our sERE and the most appropriate BIA frequencies for measuring FFM in APTs.

Acknowledgements

This study is part of the ICT innovative company technology development support project supported by the Ministry of Science and ICT in 2020 (2019-0-01758).

\section{References}

Achamrah N, Colange G, Delay J, Rimbert A, Folope V, Petit A, Grigioni S, Déchelotte P, and Coëffier M. 2018. Comparison of body composition assessment by DXA and BIA according to the body mass index: A retrospective study on 3655 measures. PLoS ONE 13:e0200465. 10.1371/journal.pone.0200465

Ainsworth BE, Stolarczyk LM, Heyward VH, Berry CB, Irwin ML, and Mussulman LM. 1997. Predictive accuracy of bioimpedance in estimating fat-free mass of African-American women. Med Sci Sports Exerc 29:781-787. 10.1097/00005768-199706000-00008

Beattie P, Isaacson K, Riddle DL, and Rothstein JM. 1990. Validity of derived measurements of leg-length differences obtained by use of a tape measure. Phys Ther 70:150-157. 10.1093/ptj/70.3.150

Beaudart $C$, Bruyère $O$, Geerinck $A$, Hajaoui $M$, Scafoglieri A, Perkisas $S$, Bautmans I, Gielen $E$, Reginster JY, and Buckinx F. 2020. Equation models developed with bioelectric impedance analysis tools to assess muscle mass: A systematic review. Clin Nutr ESPEN 35:47-62. 10.1016/j.cInesp.2019.09.012

Brantlov S, Ward LC, Jødal L, Rittig S, and Lange A. 2017. Critical factors and their impact on bioelectrical impedance analysis in children: a review. J Med Eng Technol 41:22-35. 10.1080/03091902.2016.1209590

Buckinx F, Landi F, Cesari M, Fielding RA, Visser M, Engelke K, Maggi S, Dennison E, AlDaghri NM, Allepaerts S, Bauer J, Bautmans I, Brandi ML, Bruyère $O$, Cederholm T, Cerreta F, Cherubini A, Cooper C, Cruz-Jentoft A, McCloskey E, Dawson-Hughes B, Kaufman JM, Laslop A, Petermans J, Reginster JY, Rizzoli R, Robinson S, Rolland Y, Rueda R, Vellas B, and Kanis JA. 2018. Pitfalls in the measurement of muscle mass: a need for a reference standard. J Cachexia Sarcopenia Muscle 9:269-278. 10.1002/jcsm. 12268

Buckinx F, Reginster JY, Dardenne N, Croisiser JL, Kaux JF, Beaudart C, Slomian J, and Bruyère 0.2015 . Concordance between muscle mass assessed by bioelectrical 
440

441

442

443

444

445

446

447

448

449

450

451

452

453

454

455

456

457

458

459

460

461

462

463

464

465

466

467

468

469

470

471

472

473

474

475

476

477

478

479

480

481

482

483

484

485

486

487

488

489

490 impedance analysis and by dual energy X-ray absorptiometry: a cross-sectional study. BMC Musculoskelet Disord 16:60. 10.1186/s12891-015-0510-9

Bukowski EL. 2006. Atlas of Amputations and Limb Deficiencies: Surgical, Prosthetic, and Rehabilitation Principles, ed 3. Phys Ther 86:595-596. 10.1093/ptj/86.4.595

Campa F, and Toselli S. 2018. Bioimpedance Vector Analysis of Elite, Subelite, and Low-Level Male Volleyball Players. Int J Sports Physiol Perform 13:1250-1253. 10.1123/ijspp.20180039

Centomo H, Amarantini D, Martin L, and Prince F. 2008. Differences in the coordination of agonist and antagonist muscle groups in below-knee amputee and able-bodied children during dynamic exercise. J Electromyogr Kinesiol 18:487-494. 10.1016/j.jelekin.2006.11.008

Charatsi AM, Dusser P, Freund R, Maruani G, Rossin H, Boulier A, Le Bourgeois M, Chedevergne F, de Blic J, Letourneur A, Casimir G, Jais JP, and Sermet-Gaudelus I. 2016. Bioelectrical impedance in young patients with cystic fibrosis: Validation of a specific equation and clinical relevance. J Cyst Fibros 15:825-833. 10.1016/j.jcf.2016.05.004

Chin T, Sawamura S, Fujita H, Nakajima S, Oyabu H, Nagakura Y, Ojima I, Otsuka H, and Nakagawa A. 2002. Physical fitness of lower limb amputees. Am J Phys Med Rehabil 81:321-325. 10.1097/00002060-200205000-00001

Coffey L, Gallagher P, and Desmond D. 2014. Goal pursuit and goal adjustment as predictors of disability and quality of life among individuals with a lower limb amputation: a prospective study. Arch Phys Med Rehabil 95:244-252. 10.1016/j.apmr.2013.08.011

Colica C, Di Renzo L, Gualtieri P, Romano L, Costa de Miranda R, De Lorenzo A, and Purificato I. 2018. Development and cross-validation of predictive equation for estimating total body lean in children. Ann Ist Super Sanita 54:20-27. 10.4415/ann_18_01_06

Dogan MH, Karadag B, Ozyigit T, Kayaoglu S, Ozturk AO, and Altuntas Y. 2012. Correlations between sarcopenia and hypertensive target organ damage in a Turkish cohort. Acta Clin Belg 67:328-332. 10.2143/ACB.67.5.2062685

Eckard CS, Pruziner AL, Sanchez AD, and Andrews AM. 2015. Metabolic and body composition changes in first year following traumatic amputation. J Rehabil Res Dev 52:553-562. 10.1682/JRRD.2014.02.0044

Gallagher P, Allen D, and Maclachlan M. 2001. Phantom limb pain and residual limb pain following lower limb amputation: a descriptive analysis. Disabil Rehabil 23:522-530. 10.1080/09638280010029859

Guedes AD, Bianco B, Lipay MV, Callou EQ, Castro ML, and Verreschi IT. 2010. A specific bioelectrical impedance equation to predict body composition in Turner's syndrome. Arq Bras Endocrinol Metabol 54:24-29. 10.1590/s0004-27302010000100005

Hackenberg L, Hierholzer E, Potzl W, Gotze C, and Liljenqvist U. 2003. Rasterstereographic back shape analysis in idiopathic scoliosis after posterior correction and fusion. Clin Biomech (Bristol, Avon) 18:883-889. 10.1016/s0268-0033(03)00169-4

Hecht F, MedicineNet.com, and Shiel WC. 2003. Webster's New World Medical Dictionary, 3rd Edition.

Heymsfield S, Lohman T, Wang ZM, and Going SB. 2005. Human Body Composition. 2nd ed. Champaign IL Human Kinetics.

Heymsfield SB, Smith R, Aulet M, Bensen B, Lichtman S, Wang J, and Pierson RN, Jr. 1990. Appendicular skeletal muscle mass: measurement by dual-photon absorptiometry. Am J Clin Nutr 52:214-218. 10.1093/ajcn/52.2.214

Heyward VH, and Wagner DR. 2004. Applied body composition assessment. Leeds: Human Kinetics.

Heyward VH, Wagner, D. R. 2004. Applied body composition assessment: Human Kinetics, Champaign, IL.

Peer] reviewing PDF | (2020:10:53446:2:0:CHECK 21 Jan 2021) 
491

492

493

494

495

496

497

498

499

500

501

502

503

504

505

506

507

508

509

510

511

512

513

514

515

516

517

518

519

520

521

522

523

524

525

526

527

528

529

530

531

532

533

534

535

536

537

538

539

540

541

Holzer LA, Sevelda F, Fraberger G, Bluder O, Kickinger W, and Holzer G. 2014. Body image and self-esteem in lower-limb amputees. PLoS ONE 9:e92943. 10.1371/journal.pone.0092943

Isakov E, Burger H, Gregoric M, and Marincek C. 1996. Stump length as related to atrophy and strength of the thigh muscles in trans-tibial amputees. Prosthet Orthot Int 20:96-100. 10.3109/03093649609164425

Jamaluddin S, Sulaiman AR, Imran MK, Juhara H, Ezane MA, and Nordin S. 2011. Reliability and accuracy of the tape measurement method with a nearest reading of $5 \mathrm{~mm}$ in the assessment of leg length discrepancy. Singapore Med J 52:681-684.

Janssen I, Heymsfield SB, Baumgartner RN, and Ross R. 2000. Estimation of skeletal muscle mass by bioelectrical impedance analysis. J Appl Physiol (1985) 89:465-471. 10.1152/jappl.2000.89.2.465

Janssen I, Heymsfield SB, and Ross R. 2002. Application of simple anthropometry in the assessment of health risk: implications for the Canadian Physical Activity, Fitness and Lifestyle Appraisal. Can J Appl Physiol 27:396-414. 10.1139/h02-021

Jeon KC, Kim SY, Jiang FL, Chung S, Ambegaonkar JP, Park JH, Kim YJ, and Kim CH. 2020. Prediction Equations of the Multifrequency Standing and Supine Bioimpedance for Appendicular Skeletal Muscle Mass in Korean Older People. Int J Environ Res Public Health 17. 10.3390/ijerph17165847

Kafri MW, Potter JF, and Myint PK. 2014. Multi-frequency bioelectrical impedance analysis for assessing fat mass and fat-free mass in stroke or transient ischaemic attack patients. Eur J Clin Nutr 68:677-682. 10.1038/ejcn.2013.266

Kaysen GA, Zhu F, Sarkar S, Heymsfield SB, Wong J, Kaitwatcharachai C, Kuhlmann MK, and Levin NW. 2005. Estimation of total-body and limb muscle mass in hemodialysis patients by using multifrequency bioimpedance spectroscopy. Am J Clin Nutr 82:988-995. 10.1093/ajcn/82.5.988

Khalil SF, Mohktar MS, and Ibrahim F. 2014. The theory and fundamentals of bioimpedance analysis in clinical status monitoring and diagnosis of diseases. Sensors (Basel) 14:10895-10928. 10.3390/s140610895

Kopelman PG. 2000. Obesity as a medical problem. Nature 404:635-643. 10.1038/35007508

Kriemler S, Puder J, Zahner L, Roth R, Braun-Fahrländer C, and Bedogni G. 2009. Crossvalidation of bioelectrical impedance analysis for the assessment of body composition in a representative sample of 6- to 13-year-old children. European Journal of Clinical Nutrition 63:619-626. 10.1038/ejcn.2008.19

Kulkarni J, Adams J, Thomas E, and Silman A. 1998. Association between amputation, arthritis and osteopenia in British male war veterans with major lower limb amputations. Clin Rehabil 12:348-353. 10.1191/026921598672393611

Kurdibaylo SF. 1996. Obesity and metabolic disorders in adults with lower limb amputation. $J$ Rehabil Res Dev 33:387-394.

Kwak SG, and Kim JH. 2017. Central limit theorem: the cornerstone of modern statistics. Korean J Anesthesiol 70:144-156. 10.4097/kjae.2017.70.2.144

Kyle UG, Bosaeus I, De Lorenzo AD, Deurenberg P, Elia M, Gomez JM, Heitmann BL, KentSmith L, Melchior JC, Pirlich M, Scharfetter H, Schols AM, Pichard C, and Composition of the EWG. 2004a. Bioelectrical impedance analysis--part I: review of principles and methods. Clin Nutr 23:1226-1243. 10.1016/j.clnu.2004.06.004

Kyle UG, Bosaeus I, De Lorenzo AD, Deurenberg P, Elia M, Gómez JM, Heitmann BL, KentSmith L, Melchior JC, Pirlich M, Scharfetter H, Schols AMWJ, and Pichard C. 2004b. Bioelectrical impedance analysis - Part I: Review of principles and methods. Clinical Nutrition 23:1226-1243. 10.1016/j.clnu.2004.06.004

Kyle UG, Bosaeus I, De Lorenzo AD, Deurenberg P, Elia M, Gómez JM, Heitmann BL, KentSmith L, Melchior JC, Pirlich M, Scharfetter H, Schols AMWJ, and Pichard C. 2004c.

Peer) reviewing PDF | (2020:10:53446:2:0:CHECK 21 Jan 2021) 
542

543

544

545

546

547

548

549

550

551

552

553

554

555

556

557

558

559

560

561

562

563

564

565

566

567

568

569

570

571

572

573

574

575

576

577

578

579

580

581

582

583

584

585

586

587

588

589

590

591

592

Bioelectrical impedance analysis - Part II: Utilization in clinical practice. Clinical Nutrition 23:1430-1453. 10.1016/j.clnu.2004.09.012

Kyle UG, Bosaeus I, De Lorenzo AD, Deurenberg P, Elia M, Manuel Gomez J, Lilienthal Heitmann B, Kent-Smith L, Melchior JC, Pirlich M, Scharfetter H, A MWJS, and Pichard C. 2004d. Bioelectrical impedance analysis-part II: utilization in clinical practice. Clin Nutr 23:1430-1453. 10.1016/j.clnu.2004.09.012

Kyle UG, Bosaeus I, De Lorenzo AD, Deurenberg P, Elia M, Manuel Gomez J, Lilienthal Heitmann B, Kent-Smith L, Melchior JC, Pirlich M, Scharfetter H, A MWJS, Pichard C, and Espen. 2004e. Bioelectrical impedance analysis-part II: utilization in clinical practice. Clin Nutr 23:1430-1453. 10.1016/j.clnu.2004.09.012

Kyle UG, Genton L, Karsegard L, Slosman DO, and Pichard C. 2001. Single prediction equation for bioelectrical impedance analysis in adults aged 20--94 years. Nutrition 17:248-253. 10.1016/s0899-9007(00)00553-0

Lee BJ, Cha HG, and Lee WH. 2016. The effects of sitting with the right leg crossed on the trunk length and pelvic torsion of healthy individuals. J Phys Ther Sci 28:3162-3164. 10.1589/jpts.28.3162

Lee SY, Ahn S, Kim YJ, Ji MJ, Kim KM, Choi SH, Jang HC, and Lim S. 2018. Comparison between Dual-Energy X-ray Absorptiometry and Bioelectrical Impedance Analyses for Accuracy in Measuring Whole Body Muscle Mass and Appendicular Skeletal Muscle Mass. Nutrients 10. 10.3390/nu10060738

Lee SY, and Gallagher D. 2008. Assessment methods in human body composition. Curr Opin Clin Nutr Metab Care 11:566-572. 10.1097/MCO.0b013e32830b5f23

Lieberman LS. 1993. Advances in body composition assessment. By Timothy G. Lohman. vii + 150 pp. Champaign, IL: Human Kinetics Publishers, 1992. \$18.00 (paper). American Journal of Human Biology 5:593-593. 10.1002/ajhb.1310050514

Lohman TG. 1992a. Advances in Body Composition Assessment: Human Kinetics, Champaign, IL.

Lohman TG. 1992b. Advances in Body Composition Assessment.

Lukaski HC. 1996. Biological indexes considered in the derivation of the bioelectrical impedance analysis. Am J Clin Nutr 64:397s-404s. 10.1093/ajcn/64.3.397S

Matusik E, Durmala J, and Matusik P. 2016. Association of Body Composition with Curve Severity in Children and Adolescents with Idiopathic Scoliosis (IS). Nutrients 8:71. 10.3390/nu8020071

Mialich MS, Sicchieri JMF, and Junior AAJ. 2014. Analysis of Body Composition: A Critical Review of the Use of Bioelectrical Impedance Analysis. International Journal of Clinical Nutrition 2:1-10.

Mishra SC, Chhatbar KC, Kashikar A, and Mehndiratta A. 2017. Diabetic foot. Bmj 359:j5064. 10.1136/bmj.j5064

Mulasi U, Kuchnia AJ, Cole AJ, and Earthman CP. 2015. Bioimpedance at the bedside: current applications, limitations, and opportunities. Nutr Clin Pract 30:180-193. 10.1177/0884533614568155

Nalepa D, Czarkowska M, Zaluska W, Jakubowska K, and Chrusciel P. 2019. Electrical bioimpedance in patients after ischemic stroke, a civilization disease. Ann Agric Environ Med 26:46-50. 10.26444/aaem/84849

Neelly K, Wallmann HW, and Backus CJ. 2013. Validity of measuring leg length with a tape measure compared to a computed tomography scan. Physiother Theory Pract 29:487492. 10.3109/09593985.2012.755589

Nguyen QD, Fusch G, Armbrust S, Jochum F, and Fusch C. 2007. Impedance index or standard anthropometric measurements, which is the better variable for predicting fatfree mass in sick children? Acta Paediatr 96:869-873. 10.1111/j.16512227.2007.00272.x 
593 O'Sullivan SB, Schmitz TJ, and Fulk G. 2013. Physical Rehabilitation.

594 Piccoli A, Pastori G, Guizzo M, Rebeschini M, Naso A, and Cascone C. 2005. Equivalence of

595

596

597

598

599

600

601

602

603

604

605

606

607

608

609

610

611

612

613

614

615

616

617

618

619

620

621

622

623

624

625

626

627

628

629

630

631

632

633

634

635

636

637

638

639

640

641

642 information from single versus multiple frequency bioimpedance vector analysis in hemodialysis. Kidney Int 67:301-313. 10.1111/j.1523-1755.2005.00083.x

Rahman M, and Berenson AB. 2010. Accuracy of current body mass index obesity classification for white, black, and Hispanic reproductive-age women. Obstet Gynecol 115:982-988. 10.1097/AOG.0b013e3181da9423

Renstrom P, Grimby G, and Larsson E. 1983a. Thigh muscle strength in below-knee amputees. Scand J Rehabil Med Suppl 9:163-173.

Renstrom P, Grimby G, Morelli B, and Palmertz B. 1983b. Thigh muscle atrophy in below-knee amputees. Scand J Rehabil Med Supp/ 9:150-162.

Robbins CB, Vreeman DJ, Sothmann MS, Wilson SL, and Oldridge NB. 2009. A review of the long-term health outcomes associated with war-related amputation. Mil Med 174:588592. $10.7205 /$ milmed-d-00-0608

Rosenberg DE, Turner AP, Littman AJ, Williams RM, Norvell DC, Hakimi KM, and Czerniecki JM. 2013. Body mass index patterns following dysvascular lower extremity amputation. Disabil Rehabil 35:1269-1275. 10.3109/09638288.2012.726690

Ross CA. 1972. Guidelines for measurement of amputation stump length. Bulletin of Prosthetics Research:67-82.

Roubenoff R, Baumgartner RN, Harris TB, Dallal GE, Hannan MT, Economos CD, Stauber PM, Wilson PW, and Kiel DP. 1997. Application of bioelectrical impedance analysis to elderly populations. J Gerontol A Biol Sci Med Sci 52:M129-136. 10.1093/gerona/52a.3.m129

Sadeghi H, Allard P, and Duhaime PM. 2001. Muscle power compensatory mechanisms in below-knee amputee gait. Am J Phys Med Rehabil 80:25-32. 10.1097/00002060200101000-00007

Sang Gyu K, It, sup, gt, It, sup, gt, Sung-Hoon P, It, sup, gt, It, sup, and gt. 2019. Normality Test in Clinical Research. Journal of Rheumatic Diseases 26:5-11. 10.4078/jrd.2019.26.1.5

Sardinha LB, Correia IR, Magalhães JP, Júdice PB, Silva AM, and Hetherington-Rauth M. 2020. Development and validation of BIA prediction equations of upper and lower limb lean soft tissue in athletes. Eur J Clin Nutr 74:1646-1652. 10.1038/s41430-020-0666-8

Sherk VD, Bemben MG, and Bemben DA. 2010. Interlimb muscle and fat comparisons in persons with lower-limb amputation. Arch Phys Med Rehabil 91:1077-1081. 10.1016/j.apmr.2010.04.008

Silveira EA, Barbosa LS, Rodrigues APS, Noll M, and De Oliveira C. 2020. Body fat percentage assessment by skinfold equation, bioimpedance and densitometry in older adults. Arch Public Health 78:65. 10.1186/s13690-020-00449-4

Stolarczyk LM, Heyward VH, Hicks VL, and Baumgartner RN. 1994. Predictive accuracy of bioelectrical impedance in estimating body composition of Native American women. $\mathrm{Am}$ J Clin Nutr 59:964-970. 10.1093/ajcn/59.5.964

Stone PA, Flaherty SK, Aburahma AF, Hass SM, Jackson JM, Hayes JD, Hofeldt MJ, Hager CS, and Elmore MS. 2006. Factors affecting perioperative mortality and wound-related complications following major lower extremity amputations. Ann Vasc Surg 20:209-216. 10.1007/s10016-006-9009-z

Suk S, Bom PS, and Do KS. 2001. Assessment of Quality of Life in Lower Limb Amputees Using Short-Form 36. Ann Rehabil Med 25:505-513.

Tanaka NI, Miyatani M, Masuo Y, Fukunaga T, and Kanehisa H. 2007. Applicability of a segmental bioelectrical impedance analysis for predicting the whole body skeletal muscle volume. J Appl Physiol (1985) 103:1688-1695. 10.1152/japplphysiol.00255.2007

Toselli S, Marini E, Maietta Latessa P, Benedetti L, and Campa F. 2020. Maturity Related Differences in Body Composition Assessed by Classic and Specific Bioimpedance

Peer) reviewing PDF | (2020:10:53446:2:0:CHECK 21 Jan 2021) 
643

644

645

646

647

648

649

650

651

652

653

654

655

656

657

658

659

660

661

662

663

664

665

666

667

668

669

670

671
Vector Analysis among Male Elite Youth Soccer Players. Int J Environ Res Public Health 17. $10.3390 /$ ijerph17030729

Ustun TB, Chatterji S, Bickenbach J, Kostanjsek N, and Schneider M. 2003. The International Classification of Functioning, Disability and Health: a new tool for understanding disability and health. Disabil Rehabil 25:565-571. 10.1080/0963828031000137063

Walter-Kroker A, Kroker A, Mattiucci-Guehlke M, and Glaab T. 2011. A practical guide to bioelectrical impedance analysis using the example of chronic obstructive pulmonary disease. Nutrition journal 10:35. 10.1186/1475-2891-10-35

Ward LC. 2019. Bioelectrical impedance analysis for body composition assessment: reflections on accuracy, clinical utility, and standardisation. Eur J Clin Nutr 73:194-199. 10.1038/s41430-018-0335-3

Wickramasinghe VP, Lamabadusuriya SP, Cleghorn GJ, and Davies PSW. 2008. Assessment of body composition in Sri Lankan children: validation of a bioelectrical impedance prediction equation. European Journal of Clinical Nutrition 62:1170-1177. 10.1038/sj.ejcn.1602835

Woodrow G. 2009. Body composition analysis techniques in the aged adult: indications and limitations. Curr Opin Clin Nutr Metab Care 12:8-14. 10.1097/MCO.0b013e32831b9c5b

Yoo C, Kim J, Yang Y, Lee J, and Jeon G. 2016. Bioelectrical impedance analysis for severe stroke patients with upper extremity hemiplegia. J Phys Ther Sci 28:2708-2712. 10.1589/jpts.28.2708-2712

Yoo S. 2014. Complications following an amputation. Phys Med Rehabil Clin N Am 25:169-178. 10.1016/j.pmr.2013.09.003

Zachariah SG, Saxena R, Fergason JR, and Sanders JE. 2004. Shape and volume change in the transtibial residuum over the short term: preliminary investigation of six subjects. $J$ Rehabil Res Dev 41:683-694. 10.1682/jrd.2003.10.0153

Ziegler-Graham K, MacKenzie EJ, Ephraim PL, Travison TG, and Brookmeyer R. 2008. Estimating the prevalence of limb loss in the United States: 2005 to 2050. Arch Phys Med Rehabil 89:422-429. 10.1016/j.apmr.2007.11.005 
Figure 1

The testing postures and the electrode placements

(A) InBody S10 in the supine position [permitted from the manufacture] (B) Electrode placements of sound limbs (C) Electrode placements of residual limbs
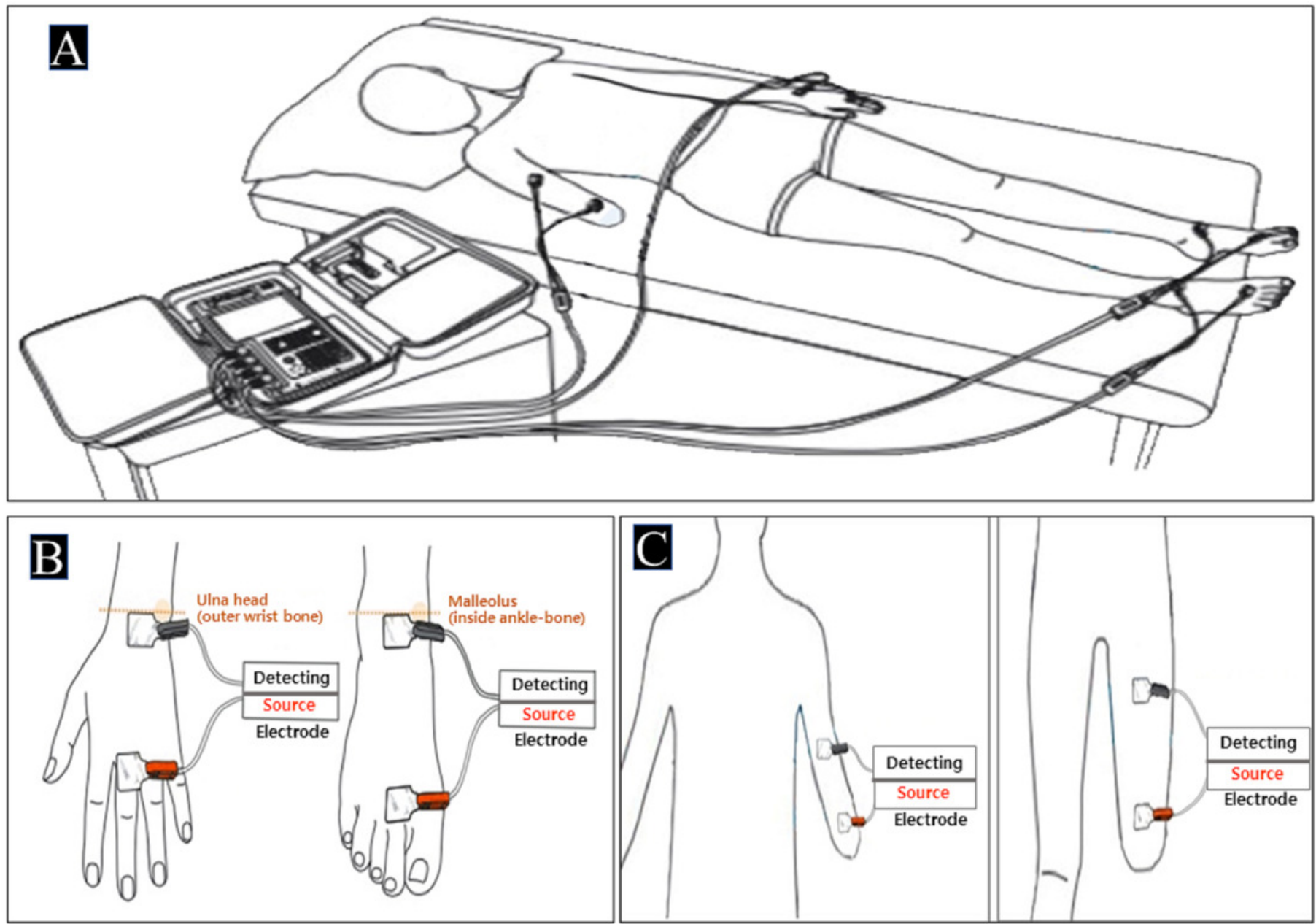
Figure 2

Bivariate linear regression for FFM values obtained using DXA and sEREs

FFM: fat-free mass $(\mathrm{kg})$, sEREs: segmental estimated regression equations, TE: total error, $r$ : validity coefficient, DXA: dual-energy X-ray absorptiometry

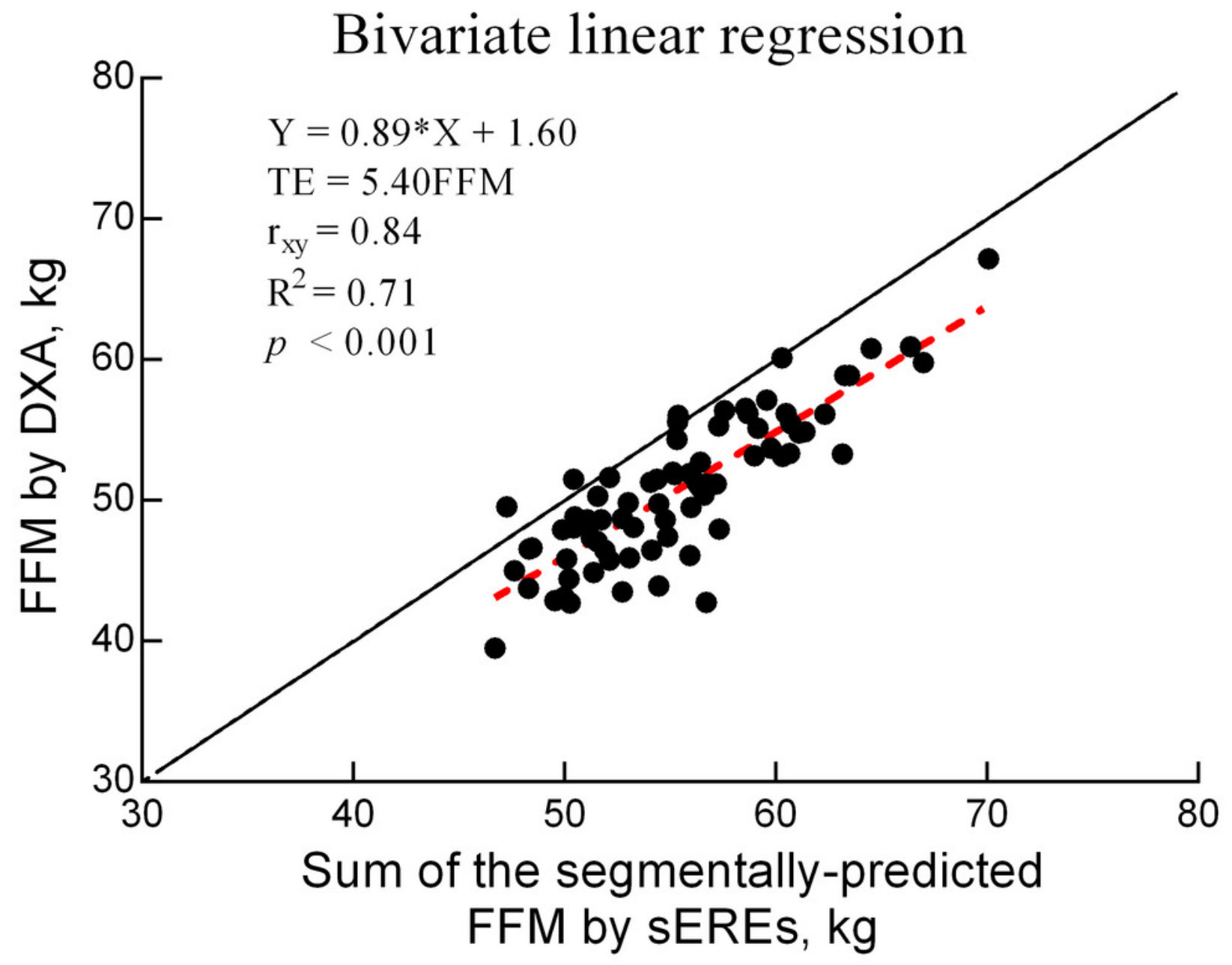


Figure 3

Bland-Altman plot

Bias: mean of DXA-BIA value, \pm 4.5 (FFM) poor $=$ "poor" standard for evaluating prediction errors, FFM: fatfree mass $(\mathrm{kg})$, DXA: dual-energy $X$-ray absorptiometry, sEREs: segmental estimated regression equations

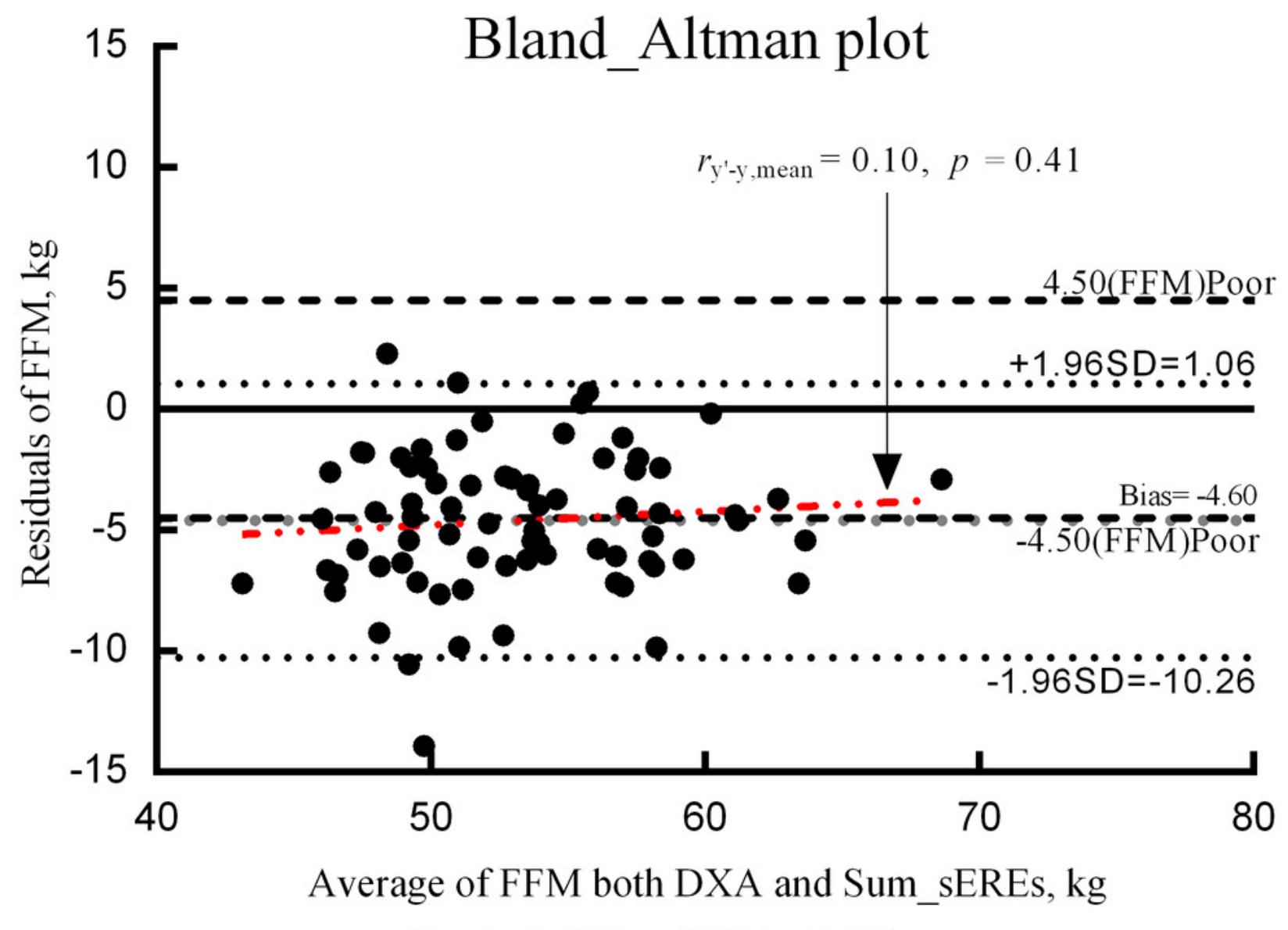

Standard of Bias of FFM: $\pm 4.50 \mathrm{~kg}=$ poor

(Lohman 1992b), (Heyward \& Wagner 2004) 
Table $\mathbf{1}$ (on next page)

Abbreviations and concepts 
Table 1. Abbreviations and concepts

\begin{tabular}{|c|c|}
\hline Abbreviation & Description \\
\hline \multicolumn{2}{|l|}{ General parameters: } \\
\hline $\mathrm{BC}$ & Body composition \\
\hline BIA & Bioimpedance analysis \\
\hline BIS & Bioimpedance spectroscopy \\
\hline BPL & Body part length \\
\hline DXA & Dual-energy X-ray absorptiometry \\
\hline ERE & Estimated regression equations \\
\hline MFBIA & Multi-frequency bioimpedance analysis \\
\hline ROI & Regions of interest \\
\hline sEREs & Segmental estimated regression equations \\
\hline SFBIA & Single-frequency bioimpedance analysis \\
\hline Sum_sEREs & $\begin{array}{l}\text { Sum of the segmentally-predicted FFM values by } \\
\text { sEREs }\end{array}$ \\
\hline \multicolumn{2}{|l|}{ Subjects parameters: } \\
\hline APTs & Amputees \\
\hline LA, RA, LL, RL, TR & $\begin{array}{l}\text { Left arm (LA), Right arm (RA), } \\
\text { Left leg (LL), Right leg (RL), Trunk (TR) }\end{array}$ \\
\hline \multicolumn{2}{|l|}{ Physiological parameters: } \\
\hline $\mathrm{BMC}$ & Bone mineral content $(\mathrm{kg})$ \\
\hline FFM & Fat-free mass (kg) \\
\hline FM & Fat mass $(\mathrm{kg})$ \\
\hline SLTM & Soft lean tissue mass $(\mathrm{kg})$ \\
\hline TBW & Total body water (L) \\
\hline \multicolumn{2}{|l|}{ BIA parameters: } \\
\hline$P A$ & Phage angle $\left(^{\circ}\right)$ \\
\hline$R$ & Resistance (Ohm, $\Omega$ ) \\
\hline$X c$ & Reactance $(\mathrm{Ohm}, \Omega$ ) \\
\hline$Z$ & Impedance $(\mathrm{Ohm}, \Omega)$. \\
\hline$Z I$ & Impedance index $\left(\mathrm{ZI}=\mathrm{Height}^{2} / \mathrm{Z}\right)$ \\
\hline \multicolumn{2}{|c|}{ Statistical analysis parameters: } \\
\hline LOA & Limits of agreement \\
\hline$R^{2}$ & Coefficient of determination \\
\hline SEE & Standard error of estimate \\
\hline$T E$ & Total error \\
\hline
\end{tabular}


Table 2 (on next page)

Participant characteristics

*Mean \pm SD; APTs: amputees; BMI: body mass index; SD: standard deviation 
Table 2. Participant characteristics

\begin{tabular}{ccccc}
\hline & \multicolumn{2}{c}{ Upper-limb APTs $(\mathrm{n}=17)$} & \multicolumn{2}{c}{ Lower-limb APTs $(\mathrm{n}=58)$} \\
& $\begin{array}{c}\text { Trans-humeral } \\
(\mathrm{n}=5)\end{array}$ & $\begin{array}{c}\text { Trans-radial } \\
(\mathrm{n}=12)\end{array}$ & $\begin{array}{c}\text { Trans-femoral } \\
(\mathrm{n}=32)\end{array}$ & $\begin{array}{c}\text { Trans-tibial } \\
(\mathrm{n}=26)\end{array}$ \\
Age (year) & $42.6 \pm 5.7 *$ & $50.4 \pm 11.6$ & $41.1 \pm 13.3$ & $43.6 \pm 10.5$ \\
Height $(\mathrm{cm})$ & $174.6 \pm 4.2$ & $168.3 \pm 7.2$ & $172.0 \pm 5.9$ & $171.4 \pm 5.6$ \\
Weight $(\mathrm{kg})$ & $78.7 \pm 4.0$ & $74.2 \pm 7.6$ & $73.7 \pm 13.7$ & $73.2 \pm 12.5$ \\
BMI $\left(\mathrm{kg} / \mathrm{m}^{2}\right)$ & $25.9 \pm 2.3$ & $26.2 \pm 2.0$ & $24.8 \pm 3.8$ & $24.9 \pm 3.6$ \\
Residual limb & $21.4 \pm 3.1$ & $42.7 \pm 4.9$ & $34.6 \pm 6.2$ & $62.2 \pm 6.7$ \\
Length $(\mathrm{cm})$ & & & & \\
Onset $(\mathrm{year})$ & $13.6 \pm 7.9$ & $16.8 \pm 11.8$ & $13.2 \pm 11.9$ & $18.2 \pm 13.9$ \\
*Mean \pm SD; APTs: amputees; BMI: body mass index; SD: standard deviation & \\
\hline
\end{tabular}




\section{Table 3 (on next page)}

The Final segmental estimated regression equations for FFM $(\mathrm{kg})$

FFM: fat-free mass $(\mathrm{kg}) ; \mathrm{ZI}_{\mathrm{BP}}$ : body part length impedance index; $\mathrm{Z}_{\mathrm{BPL}}$ : impedance; $\mathrm{XC}_{\mathrm{BP}}$ : reactance; $\mathrm{R}_{\mathrm{BPL}}$ : resistance; LA: left arm; RA: right arm; TR: trunk; LL: left leg; RL: right leg; Adj.: Adjusted; VIF: variation inflation factor; SEE: standard error estimate (kg) 
Table 3. The Final segmental estimated regression equations for FFM (kg)

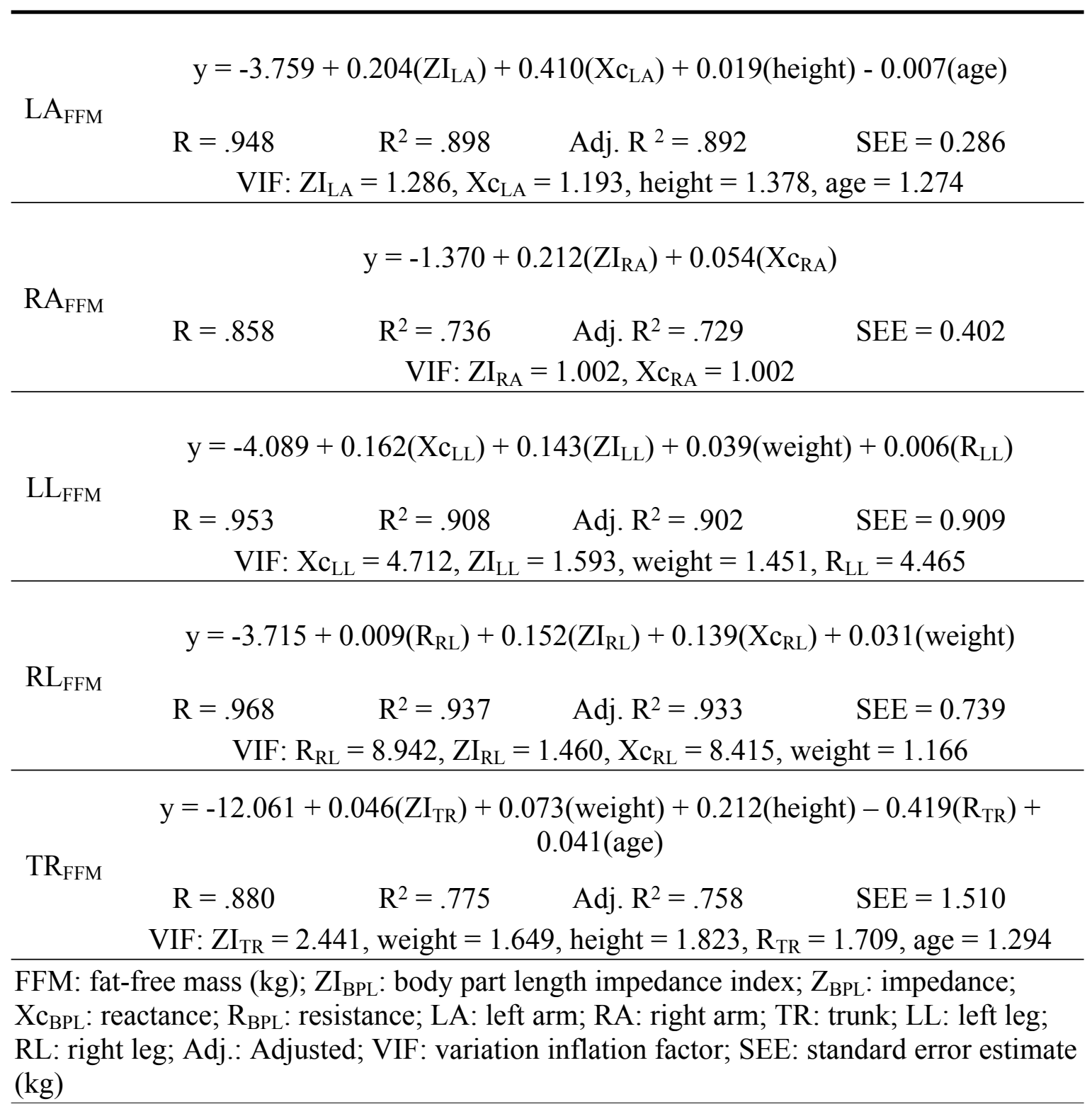

